\title{
Beneficial immune-regulatory effects of novel strains of Aureobasidium pullulans AFO-202 and N-163 produced beta glucans in Sprague Dawley rats
}

\author{
Nobunao Ikewaki \\ Kyushu University of Health and Welfare \\ Kadalraja Raghavan \\ Sarvee Integra Private Limited \\ Vidyasagar Devaprasad Dedeepiya \\ Nichi-In Centre for Regenerative Medicine (NCRM) \\ Suryaprakash Vaddi \\ Yashoda Hospitals \\ Masaru Iwasaki \\ University of Yamanashi - School of Medicine

\section{Senthilkumar Preethy} \\ Nichi-In Centre for Regenerative Medicine (NCRM)

\section{Rajappa Senthilkumar} \\ Nichi-In Centre for Regenerative Medicine (NCRM) \\ Samuel JK Abraham ( $\nabla$ drsam@nichimail.jp ) \\ University of Yamanashi - School of Medicine
}

\section{Short Report}

Keywords: Beta glucans, Aureobasidium pullulans, AFO-202, N-163, neutrophil to lymphocyte ratio (NLR), lymphocyte to c-reactive protein ratio (LCR), leucocyte to c-reactive protein ratio (LeCR)

Posted Date: August 2nd, 2021

DOI: https://doi.org/10.21203/rs.3.rs-771315/v1

License: (c) (i) This work is licensed under a Creative Commons Attribution 4.0 International License. Read Full License

Version of Record: A version of this preprint was published at Clinical Immunology Communications on November 1st, 2021. See the published version at https://doi.org/10.1016/j.clicom.2021.11.001. 


\section{Abstract}

\section{Background:}

Immune system dysregulation plays a significant role in the pathogenesis of COVID-19. A balanced immune response is essential to mounting anti-viral defences, and biomarkers such as the white blood cell (WBC) count, the neutrophil-to-lymphocyte ratio (NLR) and the lymphocyte-to-C-reactive-protein (LCR) ratio have been reported as potential predictors of immune status. The beneficial immunomodulation effects of a biological response modifier glucan (BRMG) produced by two strains of Aureobasidium pullulans, AF0-202 and N-163, were reported in earlier in vitro studies. In this study, we compared their efficacy on immune-inflammatory parameters in Sprague Dawley (SD) rats.

\section{Methods:}

This study was performed on four groups of healthy SD rats, with six subjects in each group: Group 1, which was euthanised on Day 0 to obtain baseline values; Group 2, which served as the control (drinking water); Group 3, which received AFO-202 beta glucan at a dose of $200 \mathrm{mg} / \mathrm{kg} /$ day; and Group 4, which received N-163 beta glucan at a dose of $300 \mathrm{mg} / \mathrm{kg} /$ day. Test solutions were administered to the animals in Groups 2-4 by gavage once daily for 28 consecutive days. Biochemical analyses were conducted on haematological, immunological and inflammatory biomarkers on Days 15 and 29.

\section{Results:}

The NLR decreased, whereas the LCR and leukocyte-to-C-reactive protein ratio (LeCR) increased in Group 3 (AFO202) at 15 days, but the values were within the normal physiological range only. At 29 days, this difference among the groups was not observed. There were no significant differences between the groups in the other parameters, such as red blood cell (RBC) count, WBC count, CRP, IgA, IL-6, IFN-Y and sFAS.

\section{Conclusion:}

AFO-202 beta glucan helps marginally decrease NLR and increase LCR and LeCR in healthy SD rats within 15 days. This might be beneficial to tackling infections such as COVID-19 that involve immune system dysregulation. These results warrant further investigations in larger numbers of healthy and diseased models to develop appropriate strategies for balancing immune system dysregulation using these beta glucan food supplements with proven safety.

\section{Introduction}

A balanced, robust immune system is essential for fighting infections. In particular, with the ongoing COVID-19 pandemic, immunity and inflammation play critical roles in the progression of the disease, and they influence the efficacy of management strategies [1, 2]. Immunomodulation must be balanced to overcome the cytokine storm and mount an anti-viral defence [3]. A meta-analysis of nearly 3000 COVID-19 studies revealed a significant decrease in lymphocytes, monocytes, eosinophil, haemoglobin, platelets, albumin, serum sodium, the lymphocyteto-C-reactive-protein ratio (LCR), the leukocyte-to-C-reactive-protein ratio (LeCR) and the leukocyte-to-IL-6 ratio (LeIR), as well as an increase in neutrophil, alanine aminotransferase (ALT), aspartate aminotransferase (AST), total bilirubin, blood urea nitrogen (BUN), creatinine (Cr), erythrocyte sedimentation rate (ESR), C-reactive protein (CRP), procalcitonin (PCT), lactate dehydrogenase (LDH), fibrinogen, prothrombin time (PT), D-dimer, glucose level, 
and the neutrophil-to-lymphocyte ratio (NLR) in patients with severe COVID-19 compared to those with mild or moderate disease [4]. However, there were no significant differences between the groups in terms of white blood cells (WBCs) count, creatine kinase (CK), troponin I, myoglobin or IL-6. Thus, among the various biomarkers reflecting the underlying immune and inflammatory status, LCR, NLR and LeCR have been reported by other studies and can be considered to be highly useful predictors of the impending clinical deterioration and mortality in COVID$19[5,6]$. Therapies aimed at controlling the inflammatory and dysfunctional immune response in COVID-19 mainly involve steroids [7], which have potential side effects.

Beta glucans are unique immunomodulatory compounds with established beneficial metabolic effects. Beta glucans derived from two strains of black yeast (Aureobasidium pullulans), AFO-202 and N-163, have been reported to alleviate metabolic mediators of inflammation such as glucotoxicity and lipotoxicity in animal and human clinical studies [8-10]. In particular, the ability of N-163 derived beta glucan to alleviate lipotoxicity in terms of inflammatory associated non-esterified fatty acids (NEFA) was recently demonstrated in an animal model of obese diabetic KK-Ay mice [10]. The immune-modulatory ability of AFO-202 beta glucan to stimulate the production of interleukin-8 (IL-8) and soluble Fas (sFas) while suppressing IL-1 beta, IL-2, IL-6, IL-12 (p70 + 40), interferongamma (IFN-gamma), tumour necrosis factor-alpha (TNF-alpha) and soluble Fas ligand (sFasL) has been reported in cultured peripheral blood mononuclear cells and cells of the human monocyte-like cell line, U937 [11]. In the current study, we investigated the differential effects of AFO-202 and N-163 beta glucans on immunological and inflammatory parameters in a healthy animal model.

\section{Methods}

Protocol approval was obtained from the ethics committee of Toya Laboratory, HOKUDO Co. (Ref no: HKD47055). This study was conducted in accordance with the HOKUDO Animal Experiment Regulations. The following standards for the reliability of application materials were followed: Article 43 of the Pharmaceutical Affairs Enforcement Regulations (February 1, 1957: Ministry of Health and Welfare Ordinance No. 1; last revision: August 30, 2012: Ministry of Health, Labour and Welfare Ordinance No. 120).

Six-week-old Sprague Dawley (SD)/Jcl rats (Nippon Clare Co., Japan) were used in the study. At the start of the experiment, the animals weighed 188.8 to $217.3 \mathrm{~g}$. Their general condition was observed at the time of arrival, and those with no abnormalities were acclimatised for about one week from the date of arrival. During the acclimation period, the animals' general condition was observed daily, and healthy animals with no abnormalities were used for the study. These were divided into four groups (six male animals per group) using a weight stratified randomisation method so that the average weight of each group was as uniform as possible. The animals were kept in a rearing environment with a room temperature of $23 \pm 2^{\circ} \mathrm{C}$ (acceptable limit range: $20-26^{\circ} \mathrm{C}$ ), relative humidity of $55 \pm 10 \%$ (acceptable limit range: 30-70\%), and 12 hours each of light and dark (lighting hours: 7:00 a.m. to 7:00 p.m.). The rats were housed in plastic cages $(\mathrm{W} 26 \times \mathrm{D} 31 \times \mathrm{H} 18 \mathrm{~cm}$ ) with bedding (bedding chips, Dohoh Rika Sangyo Co., Ltd.), one animal in each cage. The cage and bedding were changed at least once a week.

The animals were fed a solid feed, CE-2 (Feed One Co., Ltd., Japan), which was less than one year old. Drinking water was ground water that was sterilised by adding sodium hypochlorite to achieve a residual chlorine level of 0.3-0.4 mg/L using a facility water steriliser (MJ25SR, Kawamoto Manufacturing Co., Ltd., Japan). The water bottles were changed at least twice a week.

The groups and doses of the test substances were as follows: 
Group $1(n=6)$ : Euthanised on Day 0 for baseline values

Group $2(\mathrm{n}=6)$ : Control (solvent-drinking water)

Group $3(\mathrm{n}=6)$ : AFO-202 beta glucan-200 mg/kg/day; $20 \mathrm{mg} / \mathrm{ml}$ concentration in solution

Group $4(\mathrm{n}=6)$ : $\mathrm{N}-163$ beta glucan-300 $\mathrm{mg} / \mathrm{kg} / \mathrm{day} ; 30 \mathrm{mg} / \mathrm{ml}$ concentration in solution

The dose of each test substance was determined to be equivalent to the estimated daily intake dose for humans, which is $10 \mathrm{~g}$ in gel form for AFO-202 beta-glucan ( $5 \mathrm{mg}$ of active ingredient of beta-glucan per gm) and $15 \mathrm{~g}$ in gel form for $\mathrm{N}-163$ beta-glucan ( $6 \mathrm{mg}$ of active ingredient of beta-glucan per gm).

Because the test substances are food materials, oral administration was selected. The dosing method was gavage, which is commonly used for oral administration in rodents. The administration period was 28 days. A gastroscope (Fuchigami Kikai Co., Ltd.) and a disposable syringe (Terumo Co., Ltd.) were used to force the oral administration into the stomach once a day for 28 consecutive days. Six animals were weighed using an electronic balance (FX$12001, A \& D$ Co., Ltd.) on the day before the start of treatment (day 0). After that, all animals underwent laparotomy under isoflurane anaesthesia (isoflurane, Fujifilm Wako Pure Chemical Co., Ltd.), and blood was collected from the abdominal aorta. Of the blood obtained, $2 \mathrm{~mL}$ was used for haematological tests, and the rest was used for serum collection. The $2 \mathrm{~mL}$ of blood for haematological tests was dispensed into a blood collection tube designated by the laboratory. The blood for serum collection was centrifuged to obtain serum, then frozen. Haematological tests were carried out at Kishimoto Clinical Research Centre, Japan. Using the blood, measurements for blood cell count (RBC), Haematocrit ( $\mathrm{Ht}$ ) and Haemoglobin level $(\mathrm{Hb})$, average red blood cell volume (MCV) was calculated from $\mathrm{RBC}$ and $\mathrm{Ht}$. Average erythrocyte haemoglobin $(\mathrm{MCH})$ was calculated from RBC and $\mathrm{Hb}$. Mean erythrocyte haemoglobin concentration (MCHC) was calculated from $\mathrm{Ht}$ and $\mathrm{Hb}$ platelet count, white blood cell count (WBC), blood image (white blood cell image) by flow cytometry and specular examination using semiconductor laser. The cryopreserved sera were sent to Nagahama Life Science Laboratory, Nagahama Plant, Oriental Yeast Company, Japan, for the following parameters using ELISA: CRP, IL-6, IL-8 IFN and IgA. In addition, NLR was calculated using the actual number of neutrophils and lymphocytes from the WBC fraction obtained from the blood image (leukogram). The number of neutrophils was defined as the total number of rod-shaped nuclei and segmental nuclei. LCR was calculated from the lymphocyte count and CRP. LeCR was calculated from the WBC count and CRP.

Means and standard deviations per group were calculated for body weight on Days 1, 7, 14, 21 and 28; mean daily food intake during the acclimation period; and mean daily food intake on Days 3-6, 10-13, 17-20 and 24-27 of treatment. For haematological tests, NLR, CRP, IgA, IL-6, IL-8, IFN-y, sFAS and LCR in Groups 2 through 4, the mean values and standard deviations per group were calculated separately for blood samples collected on Day 15 (3 animals) and Day 29 (3 animals). In addition, group means and standard deviations were calculated for haematological tests, NLR, CRP, IgA, IL-6, IL-8, IFN-ץ, sFAS, LeCR and LCR in Group 1. The Bartlett test was used to test for equivariance using Excel statistics (Social Information Service Co., Ltd.). Equal variances were analysed using one-way ANOVA, and unequal variances were analysed with the Kruskal-Wallis test. When the one-way ANOVA identified significant differences, Dunnett's multiple comparison test method was used to compare the mean values with the control group, and test groups. The significance level was set at less than $5 \%$.

\section{Results}


In Group 1, mean body weight was $196.3 \mathrm{~g}$ on Day 0 . The average daily food intake during acclimation on Days 3 to 6 was $20.3 \mathrm{~g} /$ day. The erythrocyte count was $54410^{4} / \mu \mathrm{L}$, haemoglobin level was $11.5 \mathrm{~g} / \mathrm{dL}$, haematocrit was $40.5 \%$, MCV was $75 \mathrm{fL}, \mathrm{MCH}$ was $21.1 \mathrm{pg}, \mathrm{MCHC}$ was $28.3 \%$, platelet count was 71.9 104/ $\mu \mathrm{L}$, WBC count was 4.26 103/ $\mu \mathrm{L}$ and NLR was 0.284. LeCR was 0.014 and LCR was 1129.

No abnormalities attributable to the test substance were observed in any animal in any group.

There was no significant difference among Groups 2 through 4 in terms of body weight and food intake, and all groups performed well throughout the treatment period.

There was no significant difference in parameters (Table 1) among Groups 2 through 4 in the blood samples collected Days 15 and 29 of treatment. The RBC and WBC counts of Group 1 tended to be slightly lower than those of Groups 2 through 4 (Table 1), but since the timing of blood collection was different, a significance test was not performed. NLR was decreased in Group 3 (AFO-202) compared to the Groups 2 and 4 on Day 15 (Fig. 1). At Day 29 , there was no marked difference.

Table 1

Haematological findings in SD male rats administered with test substances orally for 28 days

\begin{tabular}{|c|c|c|c|c|c|c|c|c|c|}
\hline \multicolumn{2}{|l|}{ Groups } & \multirow{2}{*}{$\begin{array}{l}\text { RBC } \\
\left(10^{4} / \mu \mathrm{L}\right) \\
708\end{array}$} & \multirow{2}{*}{$\begin{array}{l}\mathrm{Hb} \\
(\mathrm{g} / \mathrm{dL}) \\
14.2\end{array}$} & \multirow{2}{*}{$\begin{array}{l}\mathrm{Ht} \\
(\%) \\
43.6\end{array}$} & \multirow{2}{*}{$\begin{array}{l}\text { MCV } \\
(f L) \\
67\end{array}$} & \multirow{2}{*}{$\begin{array}{l}\mathrm{MCH} \\
(\mathrm{pg}) \\
20.1\end{array}$} & \multirow{2}{*}{$\begin{array}{l}\text { MCHC } \\
(\%) \\
32.6\end{array}$} & \multirow{2}{*}{$\begin{array}{l}\text { Platelet } \\
\left(10^{4} / \mu \mathrm{L}\right) \\
73.7\end{array}$} & \multirow{2}{*}{$\begin{array}{l}\text { WBC } \\
\left(10^{3} / \mu \mathrm{L}\right) \\
6.71\end{array}$} \\
\hline 2 (Control) & Mean & & & & & & & & \\
\hline & SD & 32 & 0.2 & 0.6 & 2 & 1.1 & 0.6 & 9.9 & 1.37 \\
\hline \multirow[t]{2}{*}{3 (AFO-202) } & Mean & 722 & 14.4 & 43.9 & 68 & 19.9 & 32.7 & 75.5 & 7.29 \\
\hline & SD & 33 & 0.3 & 0.5 & 5 & 0.6 & 0.4 & 5.0 & 1.35 \\
\hline \multirow[t]{2}{*}{$4(\mathrm{~N}-163)$} & Mean & 712 & 13.9 & 43.9 & 66 & 19.5 & 31.6 & 67.6 & 5.49 \\
\hline & SD & 19 & 0.4 & 1.1 & 1 & 0.3 & 0.9 & 4.8 & 1.47 \\
\hline
\end{tabular}

The results of the differential blood cell count, CRP, and IgA for groups 2 to 4 are shown in Table 2 . There were no significant differences in the differential blood cell counts, CRP and IgA between groups. The values of these parameters were within the normal range in all groups. 
Table 2

Haematological findings (differential count), CRP and IgA in SD male rats administered with test substances orally for 28 days

\begin{tabular}{|c|c|c|c|c|c|c|c|c|}
\hline \multirow[t]{2}{*}{ Groups } & & \multicolumn{5}{|c|}{ Differential count of Leukocytes (\%) } & \multirow{2}{*}{$\begin{array}{l}\text { CRP } \\
(\mathrm{ng} / \mathrm{dL})\end{array}$} & \multirow{2}{*}{$\begin{array}{l}\lg A \\
(m g / d L)\end{array}$} \\
\hline & & Eosinophil & $\begin{array}{l}\text { Neutrophil } \\
\text { (Stab) }\end{array}$ & $\begin{array}{l}\text { Neutrophil } \\
\text { (Segment) }\end{array}$ & Lymphocyte & Monocyte & & \\
\hline \multirow{2}{*}{2} & Mean & 2.00 & 2.70 & 18.70 & 72.00 & 4.70 & 336.00 & 23.00 \\
\hline & SD & 1.00 & 1.20 & 4.20 & 2.60 & 0.60 & 33.00 & 3.00 \\
\hline \multirow{2}{*}{$\begin{array}{l}3 \text { (AFO- } \\
202)\end{array}$} & Mean & 2.70 & 3.30 & 23.70 & 64.30 & 6.00 & 360.00 & 22.00 \\
\hline & SD & 0.60 & 0.60 & 5.50 & 4.60 & 1.00 & 20.00 & 8.00 \\
\hline \multirow{2}{*}{$\begin{array}{l}4(\mathrm{~N}- \\
163)\end{array}$} & Mean & 1.70 & 3.30 & 22.70 & 67.00 & 5.30 & 314.00 & 22.00 \\
\hline & SD & 2.10 & 0.60 & 11.00 & 16.10 & 2.50 & 6.00 & 1.00 \\
\hline
\end{tabular}

Blood tests indicated no significant changes in inflammatory parameters, and no signs of inflammation were observed.

IL-8 increased slightly in Group 3 (AFO-202) compared to Group 4 (N-163) (Table 2), whereas LeCR (Fig. 2) and LCR (Fig. 3) increased slightly in Group 3 (AFO-202) compared to Groups 2 and 4 on Day 15. At Day 29, this difference was not observed.

IL-6, IFN-y and sFAS were below the limit of measurement, so it was not possible to examine whether or not they varied.

\section{Discussion}

Balancing immune enhancement and suppression is a critical issue, especially in relevance to acute exacerbation of any existing infectious disease or its sequalae. This is particularly true for COVID-19, in which, although immune enhancement to combat an invading foreign pathogen is of utmost importance, a cytokine storm driven by a hyperactivated immune system during pathogenesis can cause significant mortality unless managed [12].

Although simple immune enhancement and immunosuppression markers have been documented as associated with efficient management strategies for viral and immune-dysregulation related illnesses, the COVID-19 related immune reaction has been unique, disrupting earlier documented knowledge [12] and warranting a case-by-case personalised approach [3], which could be the future of patient management strategies.

Based on our earlier reports of AFO-202 beta glucan's immune-enhancement of and, to a certain extent, immunomodulation effects [13-16], although total immune-suppression or modulation by $\mathrm{N}-163$ beta glucan has been reported [10], we have also reported the advantages of $\mathrm{N}-163$ beta glucan in diseased models such as diabetes [10] and NASH [17], targeting markers such as IL-6.

Specific targeted molecules acting on a specific component of a biochemical pathway during immune enhancement or immune suppression have been reported by many studies [18], but their safety as a drug molecule in situations such as the COVID-19 pandemic may take longer to assess in routine clinical practice. Furthermore, a 
combination approach involving more than one molecule or agent might face technical and regulatory hurdles [19]. The advantage of the AFO-202 and N-163 beta glucans lie in their safety profile and track record as a food supplement [8-11, 13-17], as well as their efficacy on a "SOS" basis, as previously reported in two earlier studies of disease models $[10,17]$.

Having studied the specific beneficial effects of AFO-202 and N-163 individually and together in earlier disease models, in this study, we aimed to document their efficacy in a healthy animal model of SD rats. The study's limitations included the use of a healthy animal model without any metabolic pathology infection. Although a drastic change in parameters associated with immune dysregulation was not expected, this study can serve as a prelude to healthy human and diseased additional model studies, and the parameters studied here are relevant to the evolving strains of COVID-19, as well as similar viruses that may evolve in the future.

In the current study, AFO-202 beta glucan reduced NLR and increased LeCR and LCR. IL-6, IFN-y and sFAS were below the limit of measurement, so it was not possible to examine whether or not they varied. These parameters increase in response to inflammatory reactions. Because there was no sign of inflammatory response in the other parameters, it can be inferred that IL-6, IFN-y and sFAS did not change in this experiment, thus adding to the safety of AFO-202 and N-163 beta glucans.

Although NLR and LCR have been reported by several studies to be of importance $[5,6]$ and LeCR [4] has been indicated recently, their changes in COVID-19 patients are dynamic and need to be evaluated at admission, various time points of pathogenesis, at cytokine storm onset of cytokine storm and in severe disease, then compared with healthy individuals to arrive at novel solutions.

\section{Conclusion}

Beta glucans produced by the AFO-202 strain of $A$. pullulans helped decrease NLR and increase LCR and LeCR in healthy SD rats, though the parameters were within the normal physiological range. Taking into account the earlier reported advantages of $\mathrm{N}-163$ produce in immune modulation of diseased models, further validation of these beta glucans in clinical trials is recommended to evaluate the anti-inflammatory and immune homeostasis maintenance potentials to develop effective management strategies for viral infections such as COVID-19.

\section{Declarations}

\section{Funding:}

No external funding was received for the study

\section{Ethics Approval:}

The protocol approval was obtained by the ethics committee of Toya Laboratory, HOKUDO Co (Ref no: HKD47055). The study was conducted in accordance with the HOKUDO Animal Experiment Regulations following the Act on Welfare and Management of Animals (Ministry of the Environment, Japan, Act No. 105 of October 1, 1973), standards relating to the care and management of laboratory animals and relief of pain (Notice No.88 of the Ministry of the Environment, Japan, April 28, 2006) and the guidelines for proper conduct of animal experiments (Science Council of Japan, June 1, 2006).

\section{Potential Conflict of Interests:}


1. Author Samuel Abraham is a shareholder in GN Corporation, Japan which in turn is a shareholder in the manufacturing company of the Beta Glucans described in the study.

\section{Acknowledgements:}

The authors thank

a. Mr. Yasunori Ikeue, Mr. Mitsuru Nagataki and Mr. Takashi Onaka, (Sophy Inc, Kochi, Japan), for necessary technical clarifications.

b. Mr. Yoshio Morozumi, Ms. Yoshiko Amikura of GN Corporation, Japan for their liaison assistance with the conduct of the study.

c. Loyola-ICAM College of Engineering and Technology (LICET) for their support to our research work.

\section{Author Contribution Statement:}

N.I. and S.A contributed to conception and design of the study. R.S helped in literature search. S.A and S.P. drafted the manuscript. K.R, V.D., S.V. and M.I. performed critical revision of the manuscript. All the authors read, and approved the submitted version.

\section{Availability of data and material}

All data generated or analysed during this study are included in this manuscript.

\section{References}

1. Tay MZ, Poh CM, Rénia L, MacAry PA, Ng LFP. The trinity of COVID-19: immunity, inflammation and intervention. Nat Rev Immunol. 2020 Jun;20(6):363-374.

2. Florindo HF, Kleiner R, Vaskovich-Koubi D, Acúrcio RC, Carreira B, Yeini E, Tiram G, Liubomirski Y, Satchi-Fainaro R. Immune-mediated approaches against COVID-19. Nat Nanotechnol. 2020 Aug;15(8):630-645.

3. Hall MW, Joshi I, Leal L, Ooi EE. Immune modulation in COVID-19: Strategic considerations for personalized therapeutic intervention. Clin Infect Dis. 2020 Jul 1:ciaa904.

4. Ghahramani S, Tabrizi R, Lankarani KB, Kashani SMA, Rezaei S, Zeidi N, Akbari M, Heydari ST, Akbari H, Nowrouzi-Sohrabi P, Ahmadizar F. Laboratory features of severe vs. non-severe COVID-19 patients in Asian populations: a systematic review and meta-analysis. Eur J Med Res. 2020 Aug 3;25(1):30.

5. Erdogan A, Can FE, Gönüllü H. Evaluation of the prognostic role of NLR, LMR, PLR, and LCR ratio in COVID-19 patients. J Med Virol. 2021 Sep;93(9):5555-5559.

6. Ullah W, Basyal B, Tariq S, Almas T, Saeed R, Roomi S, Haq S, Madara J, Boigon M, Haas DC, Fischman DL. Lymphocyte-to-C-Reactive Protein Ratio: A Novel Predictor of Adverse Outcomes in COVID-19. J Clin Med Res. 2020 Jul;12(7):415-422.

7. Mattos-Silva P, Felix NS, Silva PL, Robba C, Battaglini D, Pelosi P, Rocco PRM, Cruz FF. Pros and cons of corticosteroid therapy for COVID-19 patients. Respir Physiol Neurobiol. 2020 Sep;280:103492. doi: 10.1016/j.resp.2020.103492.

8. Dedeepiya VD, Sivaraman G, Venkatesh AP, Preethy S, Abraham SJ. Potential effects of nichi glucan as a food supplement for diabetes mellitus and hyperlipidemia: preliminary findings from the study on three patients from India. Case Rep Med. 2012;2012:895370. 
9. Ganesh JS, Rao YY, Ravikumar R, Jayakrishnan GA, Iwasaki M, Preethy S, Abraham SJ. Beneficial effects of black yeast derived 1-3, 1-6 Beta Glucan-Nichi Glucan in a dyslipidemic individual of Indian origin-a case report. J Diet Suppl. 2014 Mar;11(1):1-6.

10. Ikewaki N, Onaka T, Ikeue Y, Nagataki M, Kurosawa G, Dedeepiya VD, Rajmohan M, Vaddi S, Senthilkumar R, Preethy S, Abraham S. Beneficial effects of the AFO-202 and N-163 strains of Aureobasidium pullulans produced 1,3 - 1,6 beta glucans on non-esterified fatty acid levels in obese diabetic KKAy mice: A comparative study.bioRxiv 2021.07.22.453362; doi: 10.1101/2021.07.22.453362

11. Ikewaki N, Fujii N, Onaka T, Ikewaki S, Inoko H. Immunological actions of Sophy beta-glucan (beta-1,3 - 1,6 glucan), currently available commercially as a health food supplement. Microbiol Immunol. 2007;51(9):86173.

12. Varchetta S, Mele D, Oliviero B, Mantovani S, Ludovisi S, Cerino A, Bruno R, Castelli A, Mosconi M, Vecchia M, Roda S, Sachs M, Klersy C, Mondelli MU. Unique immunological profile in patients with COVID-19. Cell Mol Immunol. 2021 Mar;18(3):604-612.

13. Ikewaki M, Iwasaki M, Kurosawa G, Rao KS, Beitia JL, Preethy S, Abraham SJ. $\beta$-Glucans: Wide-spectrum Immune-balancing Food-supplement-based Enteric ( $\beta$-WIFE) Vaccine Adjuvant Approach to COVID-19. Human Vaccines \& Immunotherapeutics 2021; 17(9). doi:10.1080/21645515.2021.1880210.

14. Ikewaki N, Dedeepiya VD, Iwasaki M, Abraham SJ. General Commentary: Beyond "TRIM" benefits of $\beta$-glucan by blood glucose and lipid balancing potentials in its defense Against COVID-19. doi: 10.3389/fimmu.2021.620658 (A commentary on Could the Induction of Trained Immunity by $\beta$-Glucan Serve as a Defense Against COVID- 19? Geller A and Yan J. Front. Immunol. 2020 11:1782. doi:

10.3389/fimmu.2020.01782)

15. Ikewaki N, Iwasaki M, Abraham S. Biological response modifier glucan through balancing of blood glucose may have a prophylactic potential in COVID-19 patients. Journal of Diabetes \& Metabolic Disorders 2020. doi: $10.1007 / \mathrm{s} 40200-020-00664-4$

16. Ikewaki N, Rao KS, Archibold AD, Iwasaki M, Senthilkumar R, Preethy S, Katoh S, Abraham S. Coagulopathy associated with COVID-19 - Perspectives \& Preventive strategies using a Biological Response Modifier Glucan. Thromb J. 2020. doi: 10.1186/s12959-020-00239-6.

17. Ikewaki N, Kurosawa G, Iwasaki M, Preethy S, Dedeepiya VD, Vaddi S, Senthilkumar R, Levy GA, Abraham S. Hepatoprotective effects of Aureobasidium pullulans derived Beta 1,3 - 1,6 biological response modifier glucans in a STAM- animal model of non-alcoholic steatohepatitis. bioRxiv 2021.07.08.451700; doi: 10.1101/2021.07.08.451700

18. Sanders JM, Monogue ML, Jodlowski TZ, Cutrell JB. Pharmacologic Treatments for Coronavirus Disease 2019 (COVID-19): A Review. JAMA. 2020 May 12;323(18):1824-1836. doi: 10.1001/jama.2020.6019.

19. Perazzolo S, Zhu L, Lin W, Nguyen A, Ho RJY. Systems and Clinical Pharmacology of COVID-19 Therapeutic Candidates: A Clinical and Translational Medicine Perspective. J Pharm Sci. 2021 Mar;110(3):1002-1017. doi: 10.1016/j.xphs.2020.11.019

\section{Figures}




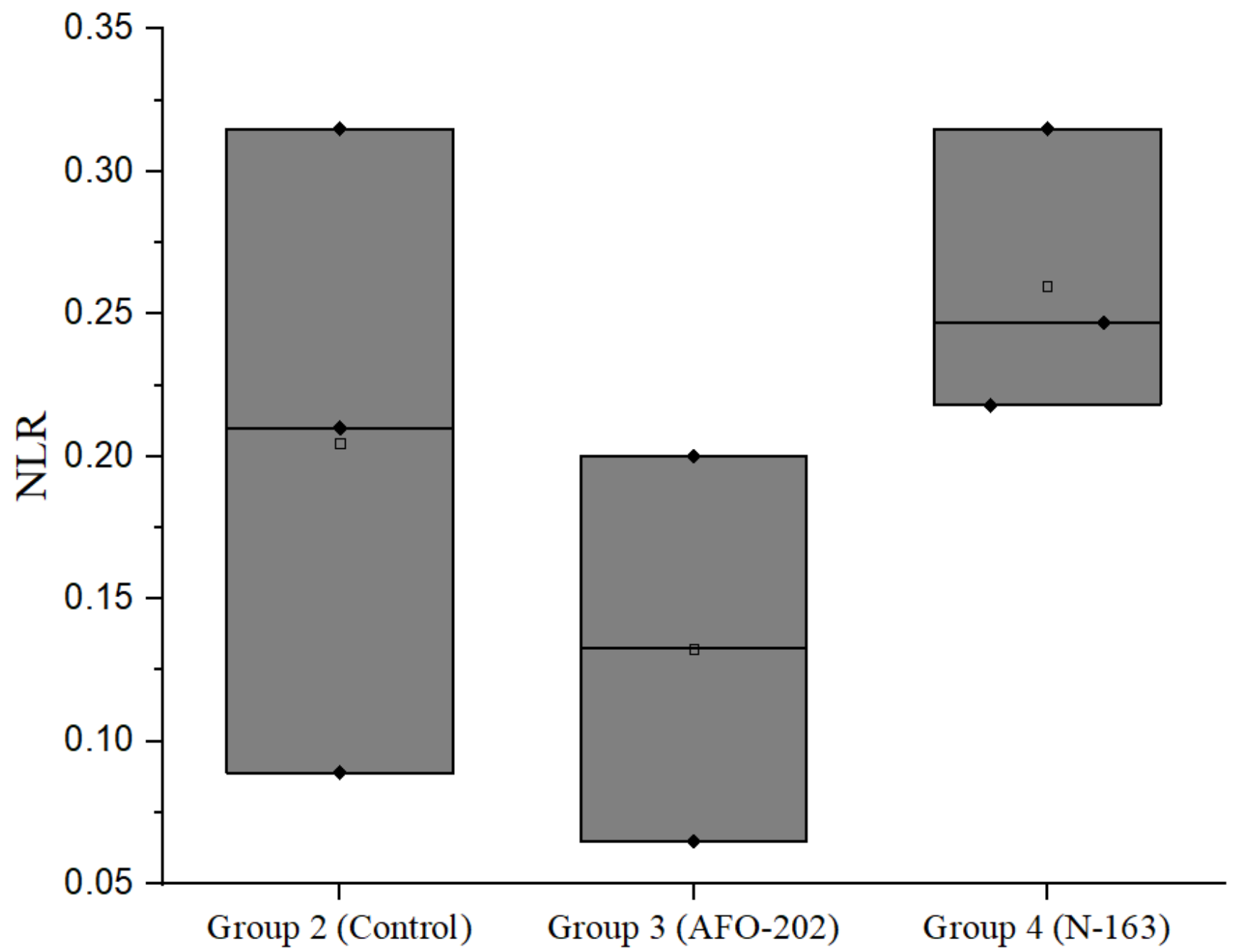

Figure 1

Neutrophil to lymphocyte ratio (NLR) decreased in group 3 (AFO-202) compared to Group 4 (N-163) and Group 2 (Control) at Day 15 of the study

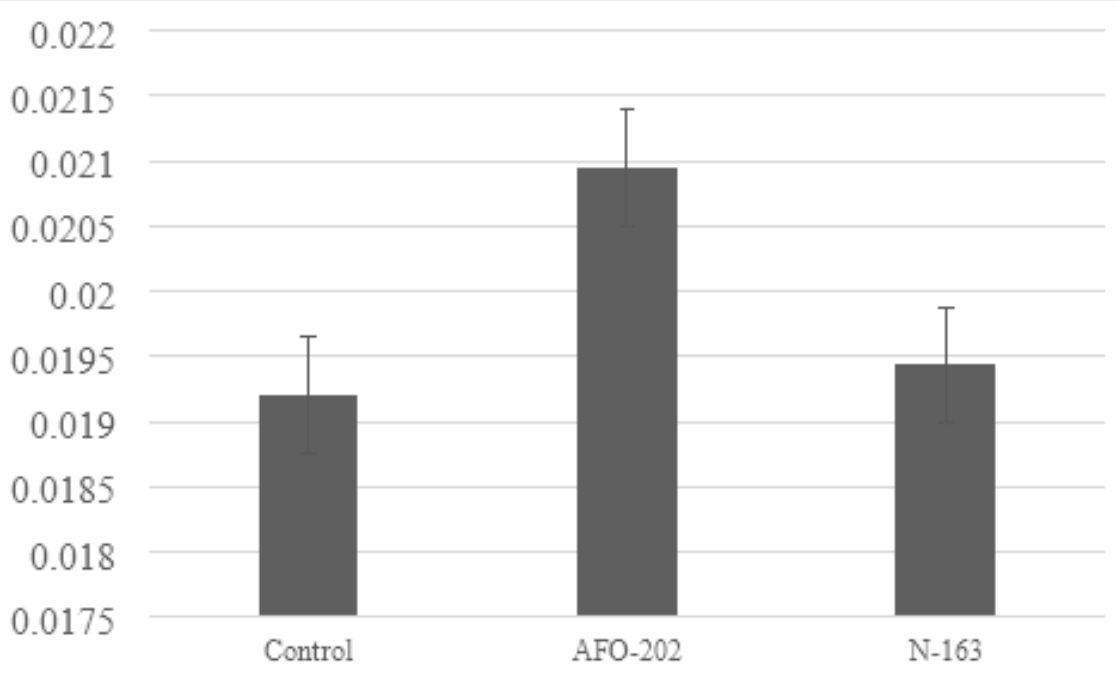


Figure 2

Leukocyte to C-reactive protein (CRP) ratio (LeCR) increased marginally in Group 4 (N-163) compared to other groups at Day 15 of the study

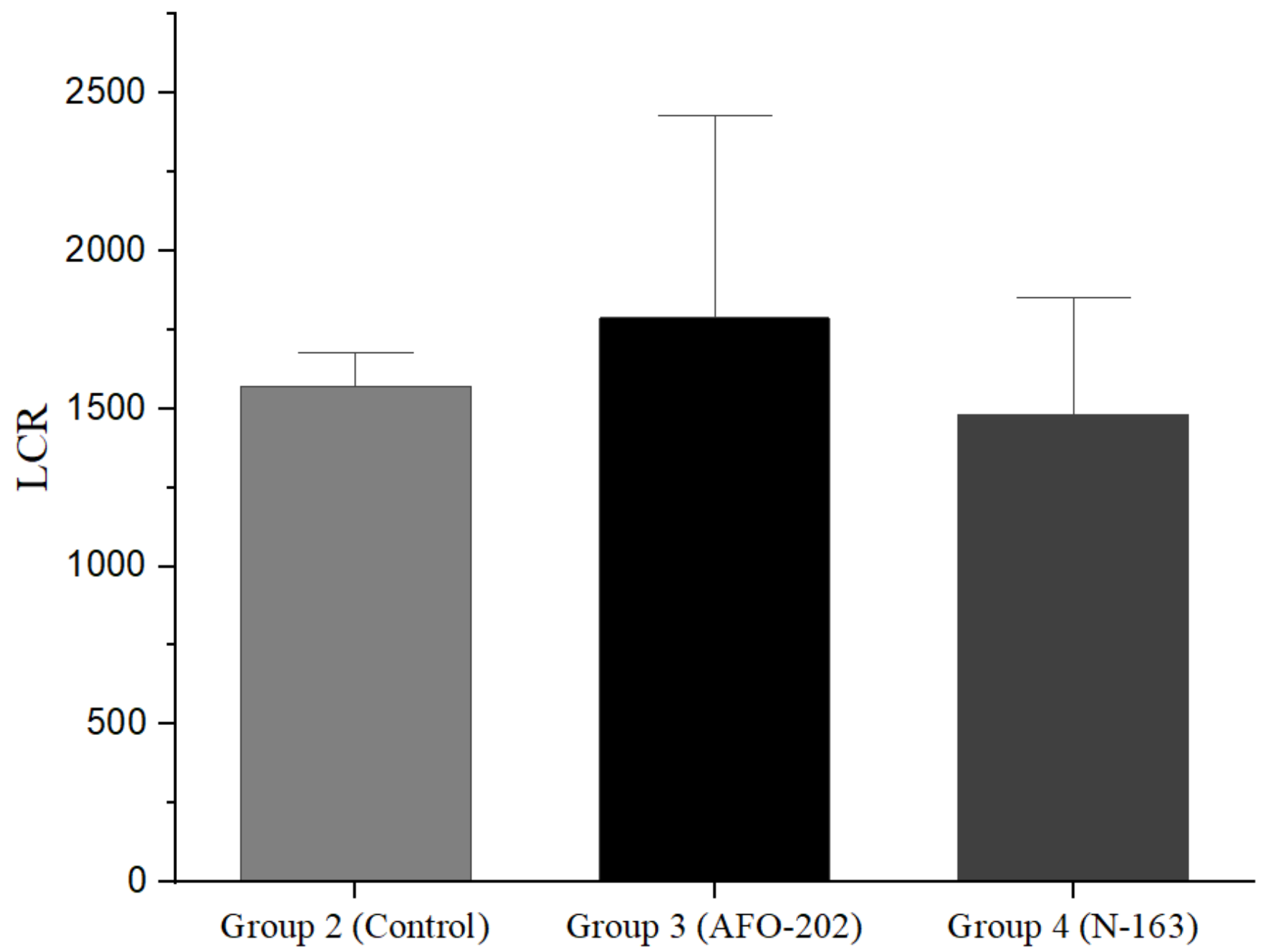

Figure 3

Lymphocyte to C-reactive protein (CRP) ratio (LCR) increased in Group 3 (AFO-202) compared to other groups at Day 15 of the study 